\title{
Platelet Function Analyzer-200 P2Y Results Are Predictive of the Risk of Major Adverse Cardiac Events in Korean Patients Receiving Clopidogrel Therapy Following Acute Coronary Syndrome
}

\author{
Hyeon-Ho Lim, M.D. ${ }^{1}$, Shuhua Li, M.D. ${ }^{2}$, Gyu-Dae An, M.D. ${ }^{1}$, Kwang-Sook Woo, M.D. ${ }^{1}$, Kyeong-Hee Kim, M.D. ${ }^{1}$, \\ Jeong-Man Kim, M.D. ${ }^{1}$, Moo-Hyun Kim, M.D. ${ }^{3}$, and Jin-Yeong Han (D, M.D. ${ }^{1}$ \\ Department of Laboratory Medicine ${ }^{1}$, Dong-A University College of Medicine, Busan, Korea; Department of Nephrology², Heilongjiang Academy of Traditional \\ Chinese Medicine, Harbin, China; Department of Cardiology ${ }^{3}$, Dong-A University College of Medicine, Busan, Korea
}

Background: Clopidogrel is one of the most commonly used anti-platelet agents in cardiovascular diseases. We analyzed the relationship between the platelet function analyzer (PFA)-200 P2Y (INNOVANCE PFA-200 System, Siemens Healthcare, Germany) results and occurrence of major adverse cardiac events (MACEs) in Korean patients with recentonset acute coronary syndrome (ACS) taking clopidogrel.

Methods: Between August 2013 and June 2016, we prospectively enrolled 106 patients with recent-onset ACS who had been treated with clopidogrel. We obtained blood samples and measured closure time (CT) using the PFA-200 P2Y test. Patients were divided into two groups on the basis of a CT cut-off value of 106 seconds. We compared patient characteristics and various MACEs that occurred during the follow-up period.

Results: The CTs for 78 patients exceeded the cut-off value. At the time of these analyses, 11 patients had been diagnosed with MACEs. In the time-to-event analysis, there was a difference between the two groups $(P<0.001)$. After adjusting other variables associated with MACE occurrence, CT value was the strongest predictor of MACEs, with a 7.30-fold occurrence risk $(P=0.002)$.

Conclusions: We found a strong relationship between CT and MACE risk in Korean patients with recent-onset ACS taking clopidogrel. Accordingly, PFA-200 P2Y results could be used as a predictive marker for MACE risk in such patients.

Key Words: PFA-200 P2Y test, Clopidogrel, Major adverse cardiac events

\author{
Received: June 27, 2017 \\ Revision received: January 10, 2018 \\ Accepted: May 3, 2018
}

Corresponding author: Jin-Yeong Han (D) https://orcid.org/0000-0003-0280-2739 Department of Laboratory Medicine, Dong-A University College of Medicine, 26 Daesingongwon-ro, Seo-gu, Busan 49201, Korea

Tel: +82-51-240-5323

Fax: +82-51-255-9366

E-mail: jyhan@dau.ac.kr

\begin{abstract}
(C) Korean Society for Laboratory Medicine This is an Open Access article distributed under the terms of the Creative Commons Attribution Non-Commercial License (http://creativecommons.org/licenses/by-nc/4.0) which permits unrestricted non-commercial use, distribution, and reproduction in any medium, provided the original work is properly cited.
\end{abstract}

\section{INTRODUCTION}

The number of Koreans with cardiovascular disease is increasing because of rapid aging and sociocultural changes such as a Westernized diet. In particular, the number of patients with acute myocardial infarction (MI) has steadily increased by approximately $30 \%$ over the past five years. This has led to a gradual increase in the economic burden and total cost of medical care benefits for patients with this disease [1].

Platelets play an important role in maintaining normal hemostasis via various mechanisms. Malfunction of these mechanisms can result in the formation of pathologic thrombi and cause vascular occlusion, leading to cardiovascular disease and ischemic stroke [2]. Clopidogrel, one of the most commonly used anti-platelet agents in cardiovascular disease, irreversibly inhibits ADP binding to platelet purinergic receptor P2Y12 [3]. 
The use of clopidogrel with acetylsalicylic acid is considered a primary therapeutic option for managing patients with recentonset acute coronary syndrome (ACS) $[4,5]$.

However, several studies have reported variable responses to clopidogrel in patients with cardiovascular disease [6-8]. Despite appropriate medical treatment with clopidogrel, major adverse cardiac events (MACEs) occur in some patients. This inter-individual response variability is often referred to as clopidogrel resistance [9]. The incidence of MACEs is higher in patients with a lower response to clopidogrel than in patients with a normal or higher response to clopidogrel [10].

Several methods are used to measure platelet function, including ADP-induced light transmittance aggregometry, the VerifyNow P2Y12 assay, Plateletworks, Multiplate analyzer, and the VASP assay; each method measures platelet activity using different properties [11, 12]. The platelet function analyzer (PFA)200 test (INNOVANCE PFA-200 System; Siemens Healthcare, Munich, Germany) is used to evaluate platelet P2Y12 receptor blockade in patients treated with a P2Y-receptor antagonist [13]. The PFA-200 test involves an easy automated process that requires a short time to obtain the test results. As it is a high-shear system using whole blood instead of platelet-rich plasma, it mimics the characteristics of physiological platelet function [14]. However, only a limited number of studies have used the PFA200 P2Y test to measure the effects of clopidogrel. In particular, no study has examined the relationship between the PFA-200 $\mathrm{P} 2 \mathrm{Y}$ results and MACEs.

We therefore analyzed the relationship between PFA-200 P2Y results and the occurrence of MACEs, including cardiac death, $\mathrm{MI}$, restenosis, and ischemic stroke. We also investigated the use of PFA-200 P2Y results as a predictor for MACE risk in patients treated with clopidogrel.

\section{METHODS}

\section{Study population and patient characteristics}

Consecutive patients diagnosed as having ACS in Dong-A University Hospital, Busan, Korea, between August 2013 and June 2016 were prospectively recruited. The inclusion criterion for this study was a diagnosis of ACS, defined as ST elevation MI, non-ST elevation $\mathrm{MI}$, and unstable angina. Patients with active bleeding, hemodynamic instability, or contraindications for antiplatelet agents were excluded. All 106 patients received percutaneous coronary intervention (PCl) using a loading dose of 300-600 mg clopidogrel. Patients who had not taken clopidogrel or aspirin were administered a loading dose of $600 \mathrm{mg}$ clopidogrel and $300 \mathrm{mg}$ aspirin. Patients who had taken $75 \mathrm{mg}$ clopidogrel and $100 \mathrm{mg}$ aspirin for longer than five days were administered a loading dose of $\mathbf{3 0 0} \mathrm{mg}$ clopidogrel. For all patients, the loading dose was administered at least four hours prior to $\mathrm{PCl}$, followed by a maintenance dose of $75 \mathrm{mg}$ clopidogrel. We obtained data on baseline characteristics, including age, sex, body mass index (BMI), underlying diseases (diabetes mellitus [DM], hypertension, dyslipidemia, and chronic kidney disease [CKD]), medical history (previous cerebrovascular accidents, $\mathrm{PCl}$, coronary artery bypass grafting, and $\mathrm{MI}$ ), lifestyle (current alcohol consumption and current smoking status), and other administered drugs. Once platelet function tests were performed, the various MACEs that occurred during the follow-up period were investigated. Clinical data were obtained from medical records. This study was approved by the Institutional Review Board of Dong-A University Hospital. Informed consent was obtained from patients prior to the collection of blood samples.

\section{Platelet function test}

Blood samples were obtained at least four hrs after the administration of a loading dose of 300-600 mg clopidogrel. Blood sampling was carried out using 21-gauge needles and vacuum tubes containing 3.2\% sodium citrate. The collection tubes were properly mixed by gently inverting them three or four times, and 800 $\mu \mathrm{L}$ of each blood sample was pipetted into the opening of the test cartridge. Platelet response to clopidogrel was evaluated using the PFA-200 P2Y test, performed within two hrs of blood sampling. The test measured the closure time (CT; second): the time required for the generated platelet plug to completely occlude the central aperture. The maximum measurable CT value was 300 seconds. The cut-off value was determined as $106 \mathrm{sec}-$ onds, according to the manufacturer's instructions [15]. Patients were divided into Group A ( $N=78$; CT value > 106 seconds) and Group B ( $N=28 ; C T$ value $\leq 106$ seconds).

\section{Statistical analysis}

Statistical analysis was performed using MedCalc for Windows, version 12.7.0.0 (MedCalc Software, Mariakerke, Belgium). $P<0.05$ was considered statistically significant. Normally distributed data were expressed as mean \pm standard deviation or number with percentage. The $\chi^{2}$ test and Fisher's exact test were used to compare baseline characteristics between the two groups. For normally distributed continuous variables, the independent t-test was used. The starting point of time-to-event analysis was the date of PCI with a loading dose of clopidogrel. The end point was the date of MACE occurrence, termination of 
follow-up, or discontinuation of clopidogrel. The remaining patients were designated as event-free. Time-to-event outcomes were analyzed using the Kaplan-Meier method, and relative risk for Group B was estimated with confidence interval (Cl). Predictors of MACEs (including CT values) were determined using Cox proportional hazards regression analysis and logistic regression analysis. Cox proportional hazards regression analysis was conducted using the following variables: PFA-200 P2Y results, BMI, underlying diseases, medical history, and lifestyle. Variables were included in the multivariate analysis, if their univariate analysis $P$ was $<0.20$. The analyses were based on the assumption that the hazard ratios for variables were proportional over time.

\section{RESULTS}

Baseline characteristics did not significantly differ between the

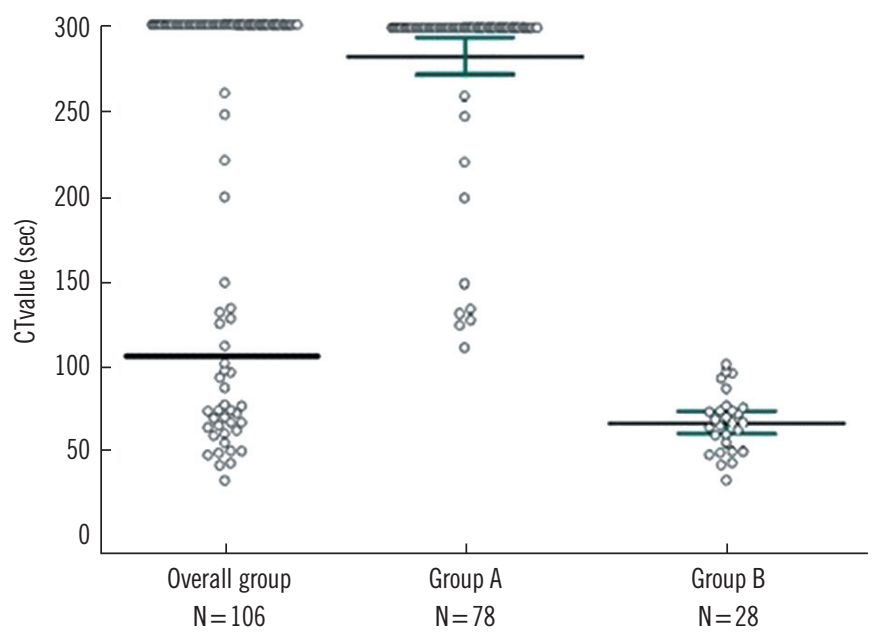

Fig. 1. Closure time (CT) value distribution of the overall group (the horizontal line indicates the analytical cut-off value of 106 seconds) and both groups separately (the horizontal lines indicate mean values and error bars indicate 95\% confidence intervals).

Table 1. Comparison of baseline characteristics of the study groups

\begin{tabular}{|c|c|c|c|c|}
\hline \multirow{2}{*}{ Variables } & \multirow{2}{*}{ Total $(\mathrm{N}=106)$} & Group A & Group B & \multirow{2}{*}{$P$} \\
\hline & & $\mathrm{CT}>106 \mathrm{sec}(\mathrm{N}=78)$ & $\mathrm{CT} \leq 106 \mathrm{sec}(\mathrm{N}=28)$ & \\
\hline \multicolumn{5}{|l|}{ Demographic characteristics } \\
\hline Age $(\mathrm{yr})$, mean $\pm S D$ & $63.4 \pm 11.1$ & $64.2 \pm 10.9$ & $61.1 \pm 11.6$ & $0.208^{*}$ \\
\hline Male, N (\%) & 77 & $56(71.8)$ & $21(75.0)$ & $0.745^{\dagger}$ \\
\hline BMI $\left(\mathrm{kg} / \mathrm{m}^{2}\right)$, mean $\pm S D$ & $24.7 \pm 2.9$ & $24.4 \pm 2.9$ & $25.5 \pm 2.6$ & $0.091^{*}$ \\
\hline \multicolumn{5}{|l|}{ Underlying diseases } \\
\hline Diabetes mellitus, N (\%) & 46 & $31(39.7)$ & $15(53.6)$ & $0.438^{\dagger}$ \\
\hline Hypertension, N (\%) & 62 & $41(52.6)$ & $21(75.0)$ & $0.306^{\dagger}$ \\
\hline Dyslipidemia, N (\%) & 32 & $20(25.6)$ & $12(42.9)$ & $0.228^{\dagger}$ \\
\hline Chronic kidney disease, $\mathrm{N}(\%)$ & 13 & $9(11.5)$ & $4(14.3)$ & $0.746^{\ddagger}$ \\
\hline \multicolumn{5}{|l|}{ Medical history } \\
\hline CVA, N (\%) & 5 & $2(2.6)$ & $3(10.7)$ & $0.132^{\ddagger}$ \\
\hline $\mathrm{PCl}, \mathrm{N}(\%)$ & 49 & $35(44.9)$ & $14(50.0)$ & $0.780^{\dagger}$ \\
\hline $\mathrm{CABG}, \mathrm{N}(\%)$ & 2 & $2(2.6)$ & $0(0.0)$ & $1.000^{\ddagger}$ \\
\hline $\mathrm{Ml}, \mathrm{N}(\%)$ & 28 & $21(26.9)$ & $7(25.0)$ & $0.880^{\dagger}$ \\
\hline \multicolumn{5}{|l|}{ Lifestyle } \\
\hline Current alcohol intake, $\mathrm{N}(\%)$ & 20 & $15(19.2)$ & $5(17.9)$ & $0.895^{\dagger}$ \\
\hline Current smoking, $\mathrm{N}(\%)$ & 23 & $18(23.1)$ & $5(17.9)$ & $0.643^{\dagger}$ \\
\hline \multicolumn{5}{|l|}{ Medication } \\
\hline ACEl or ARB, N (\%) & 27 & $15(19.2)$ & $12(42.9)$ & $0.069^{\dagger}$ \\
\hline Beta-blocker, N (\%) & 42 & $33(42.3)$ & $9(32.1)$ & $0.529^{\dagger}$ \\
\hline Calcium channel blocker, $\mathrm{N}(\%)$ & 60 & $40(51.3)$ & $20(71.4)$ & $0.346^{\dagger}$ \\
\hline Diuretics, N (\%) & 19 & $15(19.2)$ & $4(14.3)$ & $0.779^{\ddagger}$ \\
\hline Alpha-blocker, $\mathrm{N}(\%)$ & 3 & $3(3.8)$ & $0(0.0)$ & $0.568^{\ddagger}$ \\
\hline Nitrate, N (\%) & 58 & $39(50.0)$ & $19(67.9)$ & $0.392^{+}$ \\
\hline Statin, N (\%) & 73 & $51(65.4)$ & $22(78.6)$ & $0.587^{\dagger}$ \\
\hline
\end{tabular}

Calculated using an *independent t-test, ${ }^{\dagger}$ chi-squared test, and ${ }^{\ddagger}$ Fisher's exact test.

Abbreviations: CT, closure time; BMI, body mass index; CVA, cerebrovascular accident; PCI, percutaneous coronary intervention; CABG, coronary artery bypass grafting; MI, myocardial infarction; ACEI, angiotensin-converting enzyme inhibitor; ARB, angiotensin receptor blocker. 
two groups (Table 1). In Group A, the CT values of 68 patients were over the measurable upper limit of 300 seconds, while that of the other 10 patients were within the measurable range (171.5 \pm 55.3 seconds). The mean CT value of Group B was $68.9 \pm 17.5$ seconds (Fig. 1).

During this study, MACEs occurred in 11 (four Group A and seven Group B) patients (Table 2). The remaining patients were event-free at the time of analysis. The median follow-up period of the 106 patients was 493 days (range: five days to three years). The MACE incidence rate was higher in Group B (25.0\%)

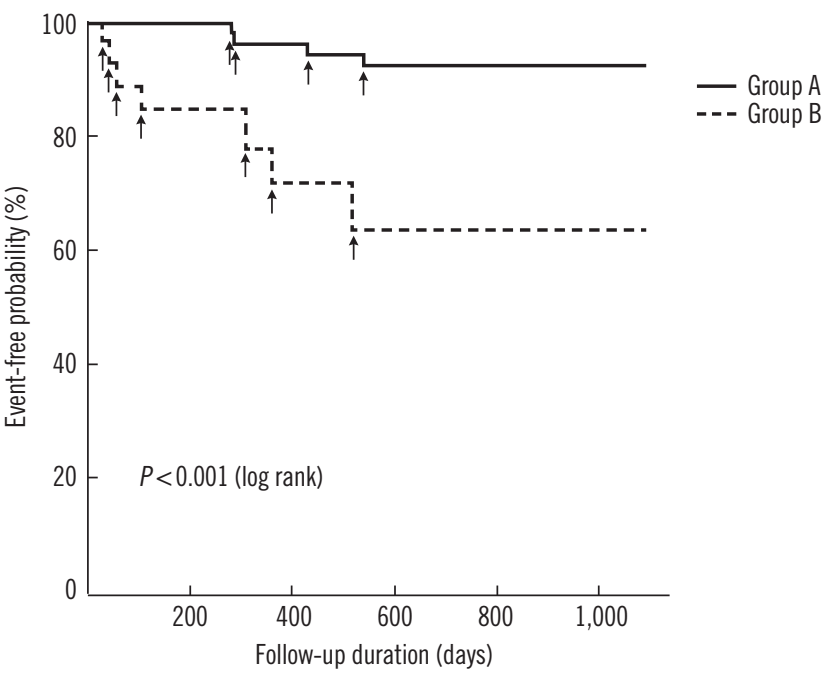

Fig. 2. Kaplan-Meier cumulative event-free curves for Group A (closure time value >106 seconds) and Group B (closure time value $\leq 106$ seconds). Each event is indicated by arrows. than in Group A (5.1\%; $P=0.009$ ). During the follow-up period, two patients were transferred to other hospitals and another two

Table 3. Cox proportional hazards regression analysis of CT and other predictors of MACE occurrence

\begin{tabular}{|c|c|c|c|c|}
\hline \multirow{2}{*}{ Variables } & \multicolumn{2}{|l|}{ Univariate } & \multicolumn{2}{|l|}{ Multivariate } \\
\hline & OR (95\% Cl) & $P$ & OR (95\% Cl) & $P$ \\
\hline \multicolumn{5}{|l|}{ PFA-200 P2Y test } \\
\hline $\mathrm{CT} \leq 106$ (sec) & 6.77 (1.98-23.12) & 0.002 & 7.30 (2.07-25.82) & 0.002 \\
\hline \multicolumn{5}{|l|}{ BMI $\left(\mathrm{kg} / \mathrm{m}^{2}\right)$} \\
\hline $23.0-24.9$ & $2.06(0.42-10.19)$ & 0.377 & & \\
\hline$\geq 25.0$ & $0.74(0.12-4.39)$ & 0.74 & & \\
\hline \multicolumn{5}{|l|}{ Underlying disease } \\
\hline Diabetes mellitus & $1.65(0.51-5.38)$ & 0.409 & & \\
\hline Hypertension & $2.23(0.59-8.36)$ & 0.237 & & \\
\hline Dyslipidemia & $1.49(0.44-5.06)$ & 0.526 & & \\
\hline Chronic kidney disease & $6.13(1.58-23.88)$ & 0.009 & $6.72(1.61-28.04)$ & 0.009 \\
\hline \multicolumn{5}{|l|}{ Medical history } \\
\hline CVA & $2.26(0.29-17.56)$ & 0.438 & & \\
\hline $\mathrm{PCl}$ & $3.17(0.85-11.87)$ & 0.089 & $2.44(0.65-9.19)$ & 0.189 \\
\hline CABG & $0.00(0.00-N / A)$ & 0.964 & & \\
\hline $\mathrm{Ml}$ & $1.14(0.31-4.29)$ & 0.842 & & \\
\hline \multicolumn{5}{|l|}{ Lifestyle } \\
\hline Current alcohol intake & $0.36(0.05-2.75)$ & 0.325 & & \\
\hline Current smoking & $0.29(0.04-2.24)$ & 0.237 & & \\
\hline
\end{tabular}

Variables were included in multivariate analysis if their univariate analysis $P$ was $<0.20$

Abbreviations: $\mathrm{CT}$, closure time; $\mathrm{OR}$, odds ratio; $\mathrm{Cl}$, confidence interval; $\mathrm{BMI}$, body mass index; CVA, cerebrovascular accident; $\mathrm{PCl}$, percutaneous coronary intervention; CABG, coronary artery bypass grafting; $\mathrm{MI}$, myocardial infarction.

Table 2. Characteristics of patients who experienced MACEs during the follow-up period

\begin{tabular}{|c|c|c|c|c|c|c|c|}
\hline Age (yr) & Sex & Diagnosis (ACS) & Underlying disease and medical history & $\mathrm{CT}(\mathrm{sec})$ & Group & MACE & Follow-up period (day) \\
\hline 57 & $\mathrm{~F}$ & NSTEMI & DM, HTN, CKD, previous PCl, previous MI & 300 & A & $\mathrm{Ml}$ & 259 \\
\hline 56 & $\mathrm{~F}$ & UA & $\mathrm{DM}$, previous $\mathrm{PCl}$ & 260 & A & Ml & 264 \\
\hline 65 & M & UA & Dyslipidemia, previous $\mathrm{PCl}$, previous MI & 300 & A & Ml & 406 \\
\hline 52 & M & UA & HTN & 300 & A & MI & 518 \\
\hline 64 & M & NSTEMI & DM, HTN, dyslipidemia, CKD & 57 & B & ischemic stroke & 5 \\
\hline 78 & M & UA & DM, HTN, CKD, CHF, previous $\mathrm{PCl}$, previous MI & 98 & B & MI & 19 \\
\hline 61 & $\mathrm{~F}$ & $U A$ & DM, HTN, dyslipidemia & 89 & B & ischemic stroke & 33 \\
\hline 74 & $\mathrm{~F}$ & UA & HTN, previous $\mathrm{PCl}$ & 52 & B & restenosis & 82 \\
\hline 64 & M & NSTEMI & DM, HTN, CHF, previous PCl & 74 & B & Ml & 284 \\
\hline 44 & M & UA & Dyslipidemia, CHF, neurofibromatosis, previous $\mathrm{PCl}$ & 35 & B & MI & 336 \\
\hline 73 & $\mathrm{~F}$ & UA & HTN, previous CVA, previous $\mathrm{PCl}$ & 52 & B & MI & 497 \\
\hline
\end{tabular}

Abbreviations: ACS, acute coronary syndrome; CT, closure time; MACE, major adverse cardiac event; NSTEMI, non-ST elevation myocardial infarction; DM, diabetes mellitus; HTN, hypertension; CKD, chronic kidney disease; UA, unstable angina; CHF, congestive heart failure; PCl, percutaneous coronary intervention; MI, myocardial infarction; CVA, cerebrovascular accident. 
patients expired from other causes (non-small cell lung cancer and biliary sepsis). A total of 16 patients discontinued clopidogrel treatment. Mild bleeding occurred in seven patients of Group A, while there were no bleeding complications in Group B. These seven patients complained of episodic easy bruising or brief localized bleeding. Their mean CT value was 300 seconds (Table 2).

Time-to-event analysis using the Kaplan-Meier method showed a difference between the two groups $(P<0.001)$. The estimated relative risk for Group B was 6.65 (95\% Cl: 1.55-28.48). The Kaplan-Meier cumulative event-free curves for the two groups are shown in Fig. 2.

The analysis showed that the significant covariates were CT value and presence of CKD. In the multivariate regression analysis, other factors had relatively low odd ratios. Results of the Cox proportional hazards regression analysis using the enter method are summarized in Table 3.

\section{DISCUSSION}

We evaluated response to clopidogrel, using the PFA-200 test. Many clinical factors could lead to a suboptimal response to clopidogrel. Baseline platelet reactivity can increase under specific conditions such as ACS, high BMI, and DM, in particular, type 1 DM [16-19]. Individual differences in clopidogrel uptake rate and the degree of conversion into active metabolites can cause response variability to clopidogrel [20]. Drug interactions are also important factors to consider. A number of studies have reported that clopidogrel-induced anti-platelet effects are hindered by lipid-soluble statins, which depend on CYP3A4-mediated metabolism [21, 22]. Other studies, however, have indicated that lipid-soluble statins do not negatively correlate with the anti-platelet effects of clopidogrel [23].

Response variability to clopidogrel is clinically significant. Its underlying mechanisms have not yet been fully elucidated [9], but are likely to be multifactorial. Hence, it is necessary to investigate whether patient baseline characteristics could have affected the present results. We found no statistically significant differences between the two groups for all baseline characteristics.

We demonstrate that a CT value $<106$ seconds was a strong predictor of MACE occurrence. Furthermore, CT value was a stronger predictor of MACE occurrence than other factors such as BMI, underlying diseases (DM, hypertension, dyslipidemia, and CKD), medical history (previous cerebrovascular accidents, $\mathrm{PCl}$, coronary artery bypass grafting, and MI), and lifestyle (cur- rent alcohol intake and current smoking). Among the latter factors, only CKD was associated with a higher risk of MACEs. CKD had a 6.13- and 6.72-fold adjusted MACE occurrence risk in our univariate and multivariate analyses, respectively, consistent with previous studies [24]. Reduced glomerular filtration rate is also associated with increased coagulability, arterial stiffness, and abnormal levels of apolipoprotein, homocysteine, and fibrinogen [25-27]. These mechanisms might influence the increased risk of MACEs.

We demonstrated that MACE incidence is increased in patients with a relatively low response to clopidogrel, compared with patients with a normal or high response to clopidogrel, because of platelet P2Y12 receptor blockade. Thus, PFA-200 P2Y results could be used as a predictive marker of MACE risk in patients treated with clopidogrel. In addition, patients with a relatively high response to clopidogrel might have a higher incidence of bleeding, although the number of patients with bleeding was not significant in our study.

The present study has some methodological limitations. The first is the small number of subjects, all of whom were recruited from a single hospital; this could have introduced selection bias. Further studies with larger populations are needed to confirm our findings. In addition, although the term "MACE" has been used to evaluate short- and long-term outcomes in many previous studies, it has no standard definition [28]. The various components of MACEs should be evaluated in more comprehensive studies with larger samples.

We also did not compare genetic background between the two groups. Various genetic polymorphisms influence the degree of drug-induced platelet inhibition [29, 30]. Polymorphisms of the CYP2C19 gene, especially CYP2C19*2, could cause low active clopidogrel metabolite levels and might be associated with a low response to clopidogrel [31, 32]. Several studies have reported a correlation between polymorphisms of the CYP2C19 gene and risk of MACEs in patients treated with clopidogrel [3335]. Future studies should also evaluate genetic background.

The PFA-200 test was not performed during the follow-up period; thus, it is also necessary to determine whether the degree of platelet P2Y12 receptor blockade is maintained at a similar level over time. In addition, the PFA-200 P2Y results have a measurable upper limit of 300 seconds; the results of 68 patients exceeded the measurable upper limit. Because of this analyzer limitation, it is difficult to proportionally correlate test results and clinical outcomes, including MACEs and bleeding tendencies.

Thus, although the PFA-200 test could be used to predict 
therapeutic response at the start of anti-platelet therapy with clopidogrel, because of the above limitations, the results of a single platelet function test might not justify treatment modification. More studies are needed to provide appropriate strategies for anti-platelet therapy for patients.

\section{Authors' Disclosures of Potential Conflicts of Interest}

No potential conflicts of interest relevant to this article were reported.

\section{Acknowledgments}

This work was supported by the National Research Foundation of Korea (NRF) grant funded by the Korea government (MSIP) (2015R1C1A2A01052751).

\section{REFERENCES}

1. Kim KM (Ed.). Health insurance review \& assessment service, healthcare bigdata hub. http://opendata.hira.or.kr/op/opc/olap3thDsInfo.do (Updated on Apr 2016).

2. Stoll G, Kleinschnitz C, Nieswandt, B. Molecular mechanisms of thrombus formation in ischemic stroke: novel insights and targets for treatment. Blood 2008;112:3555-62.

3. Hollopeter G, Jantzen HM, Vincent D, Li G, England L, Ramakrishnan V, et al. Identification of the platelet ADP receptor targeted by antithrombotic drugs. Nature 2001;409:202-7.

4. Anderson JL, Adams CD, Antman EM, Bridges CR, Califf RM, Casey DE Jr, et al. 2011 ACCF/AHA focused update incorporated into the ACC/ AHA 2007 guidelines for the management of patients with unstable angina/non-ST-elevation myocardial infarction: a report of the American College of Cardiology Foundation/American Heart Association Task Force on Practice Guidelines. Circulation 2011;123:e426-579.

5. European Association for Percutaneous Cardiovascular Interventions (EAPCI), Wijns W, Kolh P, Danchin N, Di Mario C, Falk V, et al. Guidelines on myocardial revascularization: Task Force on Myocardial Revascularization of the European Society of Cardiology (ESC) and the European Association for Cardio-Thoracic Surgery (EACTS). Eur Heart J 2010;31:2501-55

6. Gurbel PA, Bliden KP, Hiatt BL, O'Connor CM. Clopidogrel for coronary stenting: response variability, drug resistance, and the effect of pretreatment platelet reactivity. Circulation 2003;107:2908-13.

7. Järemo P, Lindahl TL, Fransson SG, Richter A. Individual variations of platelet inhibition after loading doses of clopidogrel. J Intern Med 2002; 252:233-8

8. Price MJ, Coleman JL, Steinhubl SR, Wong GB, Cannon CP, Teirstein PS. Onset and offset of platelet inhibition after high-dose clopidogrel loading and standard daily therapy measured by a point-of-care assay in healthy volunteers. Am J Cardiol 2006;98:681-4.

9. Angiolillo DJ, Fernandez-Ortiz A, Bernardo E, Alfonso F, Macaya C, Bass TA, et al. Variability in individual responsiveness to clopidogrel: clinical implications, management, and future perspectives. J Am Coll
Cardiol 2007:49:1505-16.

10. Matetzky S, Shenkman B, Guetta V, Shechter M, Beinart R, Goldenberg I, et al. Clopidogrel resistance is associated with increased risk of recurrent atherothrombotic events in patients with acute myocardial infarction. Circulation 2004;109:3171-5.

11. Renda G, Zurro M, Malatesta G, Ruggieri B, De Caterina R. Inconsistency of different methods for assessing ex vivo platelet function: relevance for the detection of aspirin resistance. Haematologica 2010;95: 2095-101

12. Lordkipanidzé M, Pharand C, Schampaert E, Turgeon J, Palisaitis DA, Diodati JG. A comparison of six major platelet function tests to determine the prevalence of aspirin resistance in patients with stable coronary artery disease. Eur Heart J 2007;28:1702-8.

13. Koessler J, Kobsar AL, Rajkovic MS, Schafer A, Flierl U, Pfoertsch S, et al. The new INNOVANCE PFA P2Y cartridge is sensitive to the detection of the P2Y12 receptor inhibition. Platelets 2011;22:20-7.

14. Choi JL, Li S, Han JY. Platelet function tests: a review of progresses in clinical application. Biomed Res Int 2014;2014:456569.

15. Tsantes A, Ikonomidis I, Papadakis I, Kottaridi C, Tsante A, Kalamara E, et al. Evaluation of the role of the new INNOVANCE PFA P2Y test cartridge in detection of clopidogrel resistance. Platelets 2012;23:481-9.

16. Angiolillo DJ, Fernandez-Ortiz A, Bernardo E, Ramírez C, Sabaté M, Jimenez-Quevedo $\mathrm{P}$, et al. Platelet function profiles in patients with type 2 diabetes and coronary artery disease on combined aspirin and clopidogrel treatment. Diabetes 2005;54:2430-5.

17. Soffer D, Moussa I, Hariai KJ, Boura JA, Dixon SR, Grines CL, et al. Impact of angina class on inhibition of platelet aggregation following clopidogrel loading in patients undergoing coronary intervention: do we need more aggressive dosing regimens in unstable angina? Catheter Cardiovasc Interv 2003;59:21-5.

18. Angiolillo DJ, Fernández-Ortiz A, Bernardo E, Barrera Ramírez C, Sabaté $\mathrm{M}$, Fernandez $\mathrm{C}$, et al. Platelet aggregation according to body mass index in patients undergoing coronary stenting: should clopidogrel loading-dose be weight adjusted? J Invasive Cardiol 2004;16:169-74.

19. Angiolillo DJ, Bernardo E, Ramírez C, Costa MA, Sabaté M, JimenezQuevedo P, et al. Insulin therapy is associated with platelet dysfunction in patients with type 2 diabetes mellitus on dual oral antiplatelet treatment. J Am Coll Cardiol 2006;48:298-304.

20. Taubert D, Kastrati A, Harlfinger S, Gorchakova O, Lazar A, von Beckerath $\mathrm{N}$, et al. Pharmacokinetics of clopidogrel after administration of a high loading dose. Thromb Haemost 2004;92:311-6.

21. Lau WC, Waskell LA, Watkins PB, Neer CJ, Horowitz K, Hopp AS, et al. Atorvastatin reduces the ability of clopidogrel to inhibit platelet aggregation: a new drug-drug interaction. Circulation 2003;107:32-7.

22. Neubauer H, Günesdogan B, Hanefeld C, Spiecker M, Mügge A. Lipophilic statins interfere with the inhibitory effects of clopidogrel on platelet function-a flow cytometry study. Eur Heart J 2003;24:1744-9.

23. Angiolillo DJ and Alfonso F. Clopidogrel-statin interaction: myth or reality? J Am Coll Cardiol 2007;50:296-8.

24. Go AS, Chertow GM, Fan D, McCulloch CE, Hsu C. Chronic kidney disease and the risks of death, cardiovascular events, and hospitalization. N Engl J Med 2004:351:1296-305.

25. Shlipak MG, Fried LF, Crump C, Bleyer AJ, Manolio TA, Tracy RP, et al. Elevations of inflammatory and procoagulant biomarkers in elderly persons with renal insufficiency. Circulation 2003;107:87-92.

26. London GM, Guérin AP, Marchais SJ, Métivier F, Pannier B, Adda H. Arterial media calcification in end-stage renal disease: impact on allcause and cardiovascular mortality. Nephrol Dial Transplant 2003;18: 1731-40.

27. Muntner P, Hamm LL, Kusek JW, Chen J, Whelton PK, He J. The prev- 
Lim H-H, et al.

Relationship between PFA-200 P2Y test and MACEs

alence of nontraditional risk factors for coronary heart disease in patients with chronic kidney disease. Ann Intern Med 2004;140:9-17.

28. Kip KE, Hollabaugh K, Marroquin OC, Williams DO. The problem with composite end points in cardiovascular studies. J Am Coll Cardiol 2008;51:701-7.

29. Angiolillo DJ, Fernandez-Ortiz A, Bernardo E, Ramírez C, Cavallari U, Trabetti E, et al. Contribution of gene sequence variations of the hepatic cytochrome P450 3A4 enzyme to variability in individual responsiveness to clopidogrel. Arterioscler Thromb Vasc Biol 2006;26:1895-900.

30. Beitelshees AL and McLeod HL. Clopidogrel pharmacogenetics: promising steps towards patient care? Arterioscler Thromb Vasc Biol 2006; 26:1681-3.

31. Hulot JS, Bura A, Villard E, Azizi M, Remones V, Goyenvalle C, et al. Cytochrome P450 2C19 loss-of-function polymorphism is a major determinant of clopidogrel responsiveness in healthy subjects. Blood 2006; 108:2244-7.

32. Li S, Choi JL, Guo LZ, Goh RY, Kim BR, Woo KS, et al. Correlation be- tween the CYP2C19 phenotype status and the results of three different platelet function tests in cardiovascular disease patients receiving antiplatelet therapy: an emphasis on newly introduced platelet function analyzer-200 P2Y test. Ann Lab Med 2016;36:42-8.

33. Trenk D, Hochholzer W, Fromm MF, Chialda LE, Pahl A, Valina CM, et al. Cytochrome P450 2C19 681G > A polymorphism and high on clopidogrel platelet reactivity associated with adverse 1 -year clinical outcome of elective percutaneous coronary intervention with drug-eluting or bare-metal stents. J Am Coll Cardiol 2008;51:1925-34.

34. Collet JP, Hulot JS, Pena A, Villard E, Esteve JB, Silvain J, et al. Cytochrome P450 2C19 polymorphism in young patients treated with clopidogrel after myocardial infarction: a cohort study. Lancet 2009;373:30917.

35. Simon T, Verstuyft C, Mary-Krause M, Quteineh L, Drouet E, Méneveau $\mathrm{N}$, et al. Genetic determinants of response to clopidogrel and cardiovascular events. N Engl J Med 2009;360:363-75. 